\title{
Role of gender, smoking profile, hypertension, and diabetes on saphenous vein and internal mammary artery endothelial relaxation in patients with coronary artery bypass grafting
}

\author{
Andrew Duncan Muir,' Pascal Patrick McKeown' and Ulvi Bayraktutan²,* \\ 'Department of Medicine; Institute of Clinical Science; Queen's University Belfast; Belfast, UK; ${ }^{2}$ Division of Stroke Medicine; Clinical Sciences Building; \\ University of Nottingham; Nottingham City Hospital Campus; Nottingham, UK
}

Key words: endothelial dys/function, coronary artery bypass grafting, internal mammary artery, saphenous vein, risk factors

Abbreviations: CABG, coronary artery bypass grafting; IMA, internal mammary artery; $\mathrm{O}_{2} \cdot-$, superoxide; $\mathrm{NO}$, nitric oxide; ROS, reactive oxygen species; SV, saphenous vein

\begin{abstract}
The aim of this study was to investigate if there was a link between the relaxant responses in saphenous vein (SV) and internal mammary artery (IMA) segments obtained from patients undergoing coronary artery bypass grafting and the patients' cardiovascular risk factors. Endothelium-(in)dependent relaxations were assessed by isometric tension studies. Endothelium-dependent relaxant responses were greater in IMA than SV and gender, smoking profile and history of hypertension but not diabetes appeared to have an influence on these responses. Endothelium-dependent relaxant responses in both IMA and SV were greater in males than females and relaxant responses in IMA segments were attenuated in smokers, whereas the opposite effect was noted in SV segments. Endothelium-dependent relaxant responses in SV were lower in patients with hypertension. Endothelium-independent relaxant responses were greater in IMA than SV. Endothelium-independent responses were greater in male patients' SV segments, but gender played no role in IMA segments. Diabetes had no effect on endothelium-independent responses in IMA, but SV segments from diabetic patients had greater responses. Neither conduit's endothelium-independent response was affected by hypertensive status. The relationship between risk factor status and endothelial responses is multifactorial, with gender, hypertension, diabetes and smoking status all contributing.
\end{abstract}

\section{Introduction}

The optimal treatment for severe coronary artery disease remains coronary artery bypass grafting (CABG). ${ }^{1}$ Differences in the patency rates of various vascular conduits including internal mammary artery (IMA) and saphenous vein (SV) and the resulting difference in patient survival when differing grafting strategies are utilized have long been recognized..$^{2-4}$ The specific factors which govern this discrepancy are not fully understood; however, the risk factors for ischaemic heart disease are believed to contribute (Fig. 1). ${ }^{5,6}$ The endothelium has long been known to play a pivotal role in the regulation of vascular tone and homeostasis, ${ }^{7}$ producing a wide array of vasoactive compounds. The ability of the conduits to adapt to oxidative stress associated with the excessive bioavailability of reactive oxygen species (ROS) is also believed to be important. ${ }^{8-12}$ The interaction between risk factor status and abnormal levels of ROS is at best complex, with $17-\beta$-estradiol eliciting vasodilatation, ${ }^{13}$ and diabetes having no effect on endothelial responses in some studies ${ }^{14}$ although changes have been demonstrated in the levels of superoxide $\left(\mathrm{O}_{2}^{-}\right)$produced by diabetic subjects. Smoking has been shown to reduce levels of nitric oxide (NO), but this was associated with increased production of nitric oxide synthase. ${ }^{15}$ Manipulation of $\mathrm{H}_{2} \mathrm{O}_{2}$ levels has been shown to produce opposite effects at differing concentration by the same group. ${ }^{16,17}$

Vascular reactivity has long been utilized as a marker of endothelial function, ${ }^{18,19}$ and this concept underpins our investigation methodology. Using isometric tension studies in human vascular samples, we sought to investigate the two commonly used CABG conduits. Our aim was to delineate if there was a correlation between the type and presence of risk factors and endothelial responses in these conduits.

Endothelium-dependent vasomotion is generally accepted as being reflective of the overall function of the endothelium, ${ }^{20}$ and is considered to be an early marker of atherosclerosis. ${ }^{21}$ A direct link between vascular responses to acetylcholine and 


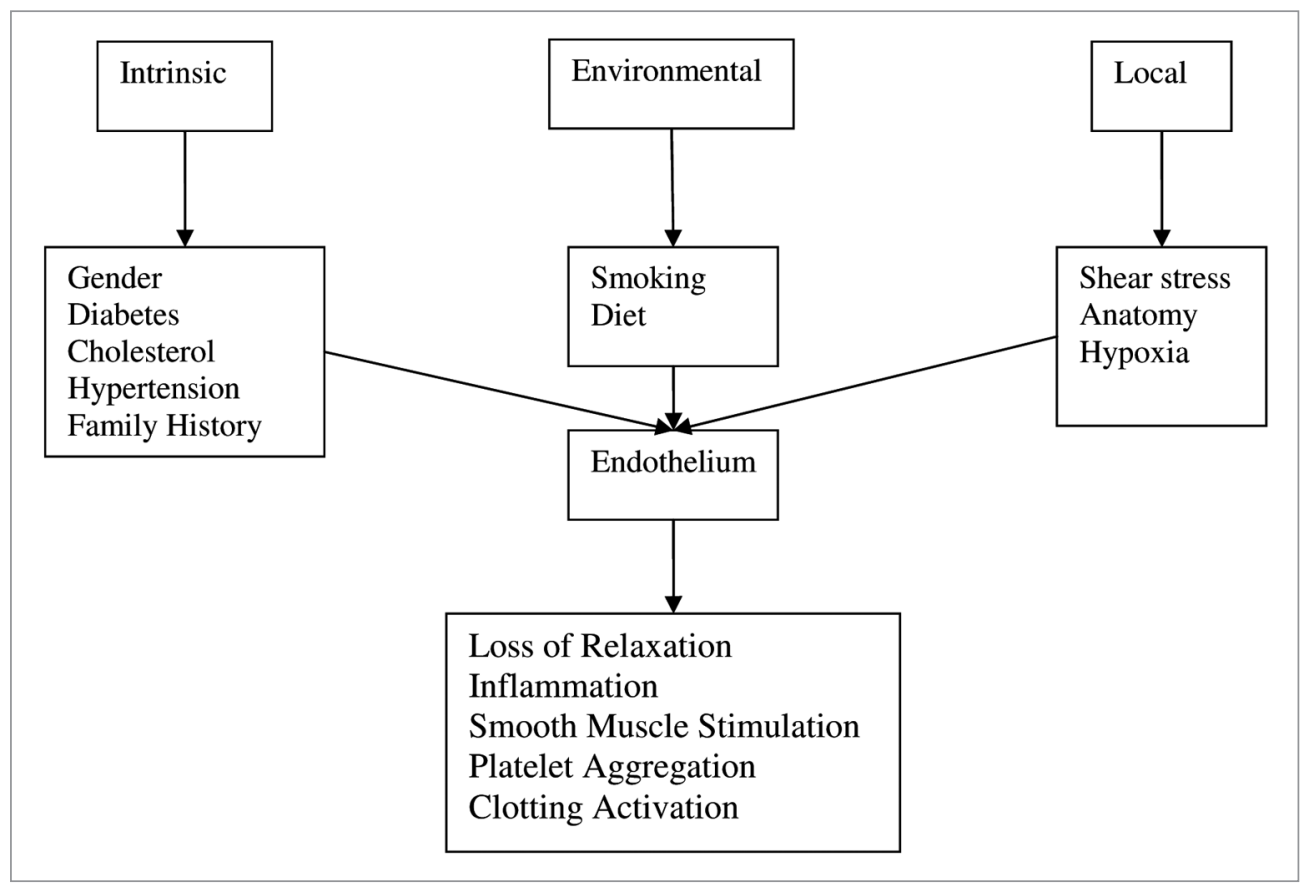

Figure 1. Schematic of the various factors with influence on the vascular endothelium as pertains to coronary artery bypass grafting.

Table 1. Breakdown of risk factors and medications by gender

\begin{tabular}{|ccc|}
\hline Characteristics & Male & Female \\
\hline Age & $29-82$ y & $44-79 y$ \\
\hline Vascular Risk Factors & 103 & 23 \\
Current Smoker & & \\
\hline Ex-Smoker & 21 & 3 \\
\hline Non-Smoker & 55 & 7 \\
\hline Diabetic & 27 & 13 \\
\hline Non-diabetic & 30 & 3 \\
\hline Hypertensive & 73 & 20 \\
\hline Non-hypertensive & 54 & 13 \\
\hline Drug therapy & 49 & 10 \\
\hline Anti-Platelet & & \\
\hline Statin & 102 & 23 \\
\hline Beta-Blocker & 97 & 22 \\
\hline ACE-Inhibitor & 88 & 19 \\
\hline Calcium Channel Blocker & 79 & 16 \\
\hline Potassium Channel Activator & 23 & 6 \\
\hline Nitrate & 50 & 11 \\
\hline Diuretic & 49 & 13 \\
\hline
\end{tabular}

Demographic breakdown and distribution of pre-operative medications for included patients. ACE-inhibitor; angiotensin converting enzyme inhibitor.

long term outlook had been demonstrated, ${ }^{22}$ therefore we chose acetylcholine to interrogate vascular responses dependent upon the endothelium. Sodium nitroprusside is a NO donor which directly affects the vascular smooth muscle, irrespective of whether the endothelium is functional, ${ }^{23}$ and it was used to elicit vascular responses independent of the endothelium.

\section{Results}

Patient characteristics. Of the 126 patients, 103 were male, 33 had diabetes mellitus and 67 were hypertensive, with 24 current and 62 ex-smokers. There was no significant difference between the ages of male (median 66y) and female (median 68y) patients (Table 1). These patients contributed a total of 449 vascular segments $(212$ IMA).

Conduit influence. Endothelium-dependent relaxant responses were greater in IMA than SV with maximal responses being $53.12 \pm 2.13 \%$ and $35.47 \pm 2.13 \%$, respectively $(p<0.05$, Fig. 2A). Similarly, endothelium-independent relaxant responses were greater in IMA $(117.30 \pm 1.64 \%$ versus $101.86 \pm 1.56 \%$, $\mathrm{p}<0.05$, Fig. 2B). Contractions to high potassium solution were significantly greater with IMA than SV $(938.3 \pm 42.4$ g versus 724.7 \pm 38.7 g per g dry tissue, $n \geq 50, p<0.05$ ).

Risk factor influence. Endothelium-dependent relaxant responses were significantly better in male compared to female patients with both IMA and SV ( $p<0.05$, Fig. 3A), whilst the endothelium-independent relaxant responses were significantly better in SV segments from male patients $(\mathrm{p}<0.05)$ but not IMA segments ( $p>0.05$, Fig. 3B).

Of the 126 patients included for analysis, 125 were on lipid modifying medication (119 were on a statin), so meaningful analysis in relation to this risk factor was not possible. With both conduits, there were no differences in endothelium-dependent relaxant responses between diabetic and non-diabetic patients (IMA, p > 0.05; SV, p > 0.05, Fig. 4A). In SV segments, however, the 

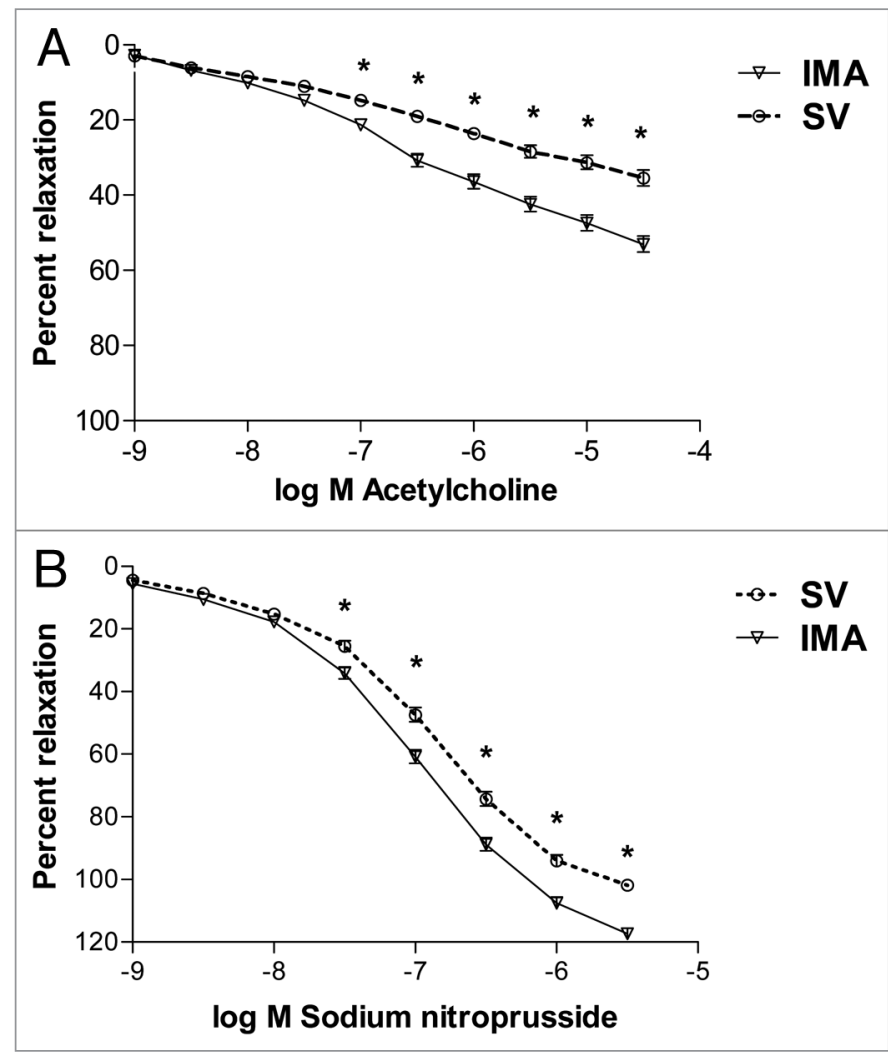

Figure 2. Endothelium-dependent (A) and -independent (B) relaxant responses are significantly greater in both internal mammary arteries (IMA; $p<0.05, n=89)$ and saphenous veins ( $S V ; p<0.05, n=92)$. Vessel segments are pre-contracted to a plateau using a sub-maximal dose of phenylephrine, then exposed to increasing concentrations of an endothelium-dependent (acetylcholine) or -independent (sodium nitroprusside) relaxant. Comparisons are made using paired repeated measures 2-way ANOVA and individual dose points are compared using Bonferroni post-hoc testing, with the indicated doses being significantly different from one another $(p<0.05)$. Results are expressed as mean \pm SEM.

endothelium-independent relaxant responses of diabetic patients were significantly better than the responses of non-diabetic patients ( $<<0.05$, Fig. 4B).

In hypertensive patients, although no significant differences were observed in IMA endothelium-dependent relaxant responses, reduced relaxation was noted in SV specifically with the highest concentration of acetylcholine ( $<<0.05$, Fig. $5 \mathrm{~A})$. With both conduits, there were no differences in endothelium-independent relaxant responses between hypertensive and non-hypertensive patients (Fig. 5B).

The relationship between smoking history and relaxant responses is complex. In IMA segments, current smokers have the worst endothelium-dependent responses, ex-smokers next and non-smokers the best $(p<0.05)$. The opposite is true for SV segments, with non-smokers having the worst endotheliumdependent responses, ex-smokers next and current smokers the best $(\mathrm{p}<0.05)$. In IMA segments, there were no differences in the endothelium-independent relaxant responses $(p>0.05)$, however, in SV segments, ex-smokers have the worst endothelium-independent responses, non-smokers next and current smokers the best

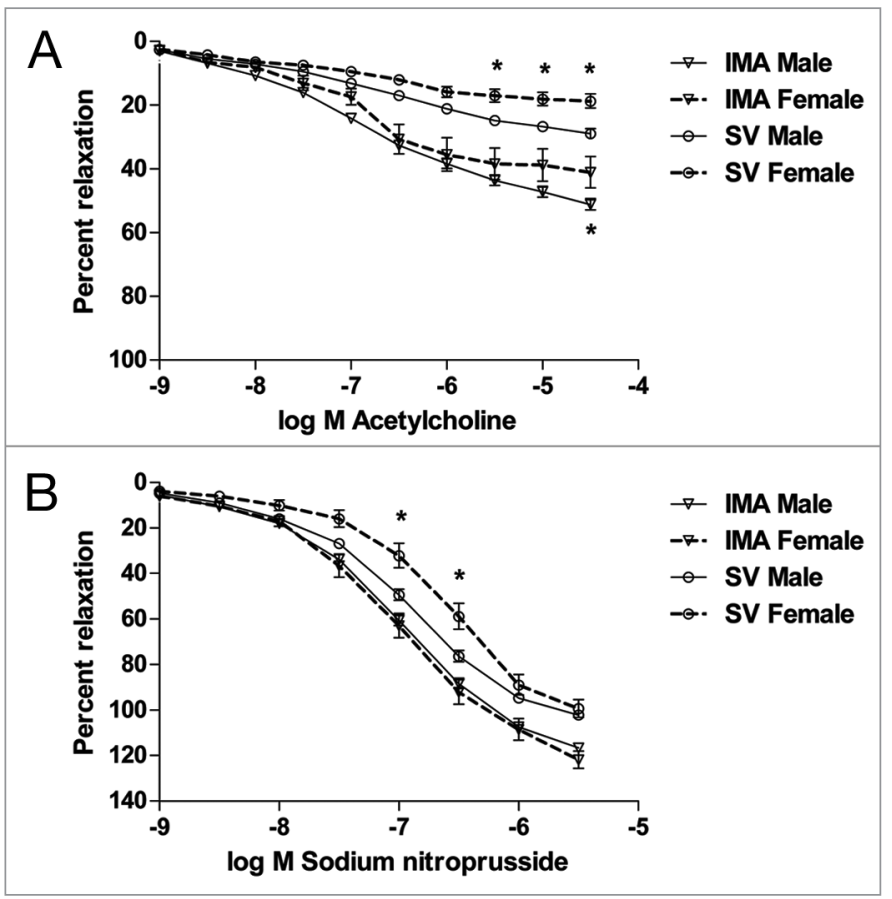

Figure 3. Endothelium-dependent relaxant responses (A) in internal mammary artery (IMA) and saphenous vein (SV) with male $(n=103)$ versus female $(n=23)$ patients, and endothelium-independent relaxant responses (B) in IMA and SV with male $(n=65)$ versus female $(n=$ 11) patients are displayed. Vessel segments are pre-contracted to a plateau using a sub-maximal dose of phenylephrine, then exposed to increasing concentrations of an endothelium-dependent (acetylcholine) or -independent (sodium nitroprusside) relaxant. Comparisons are made using unpaired repeated measures 2-way ANOVA and individual dose points are compared using Bonferroni post-hoc testing, with the indicated doses being significantly different from one another $(p<0.05$, compared to the other sex). Differences in individual data points with IMA segments are noted below the curves, whilst differences with SV segments are indicated above the curves. Both IMA and SV endothelium-dependent relaxant responses are significantly better in male compared to female patients $(p<0.05$, A). Endothelium-independent relaxant responses of SV are significantly better in male versus female patients $(p<0.05$, B) whilst no significant differences are observed with IMA segments. Results are expressed as mean \pm SEM.

$(\mathrm{p}<0.05)$. Responses in current versus non-smokers are seen in Figure 6A (endothelium-dependent: both IMA and SV p < 0.05) and 6B (endothelium-independent: both IMA and SV p > 0.05). Responses in current versus ex-smokers are seen in Figure 7A (endothelium-dependent: IMA $\mathrm{p}<0.05$ ) and $7 \mathbf{B}$ (endotheliumindependent: IMA p > 0.05, SV p < 0.05).

There were no significant differences in the contractile function of each conduit with respect to each risk factor. For example, with IMA segments, hypertensives gave $917.7 \pm 486.1 \mathrm{~g}$ versus 968.8 $\pm 474.4 \mathrm{~g}$ per $\mathrm{g}$ of dry conduit. With SV segments, diabetics gave $640.6 \pm 293.3 \mathrm{~g}$ versus $749.2 \pm 434.3 \mathrm{~g}$ per $\mathrm{g}$ of dry conduit.

\section{Discussion}

This study explicitly demonstrates that both the endotheliumdependent and independent relaxant responses of IMA segments 

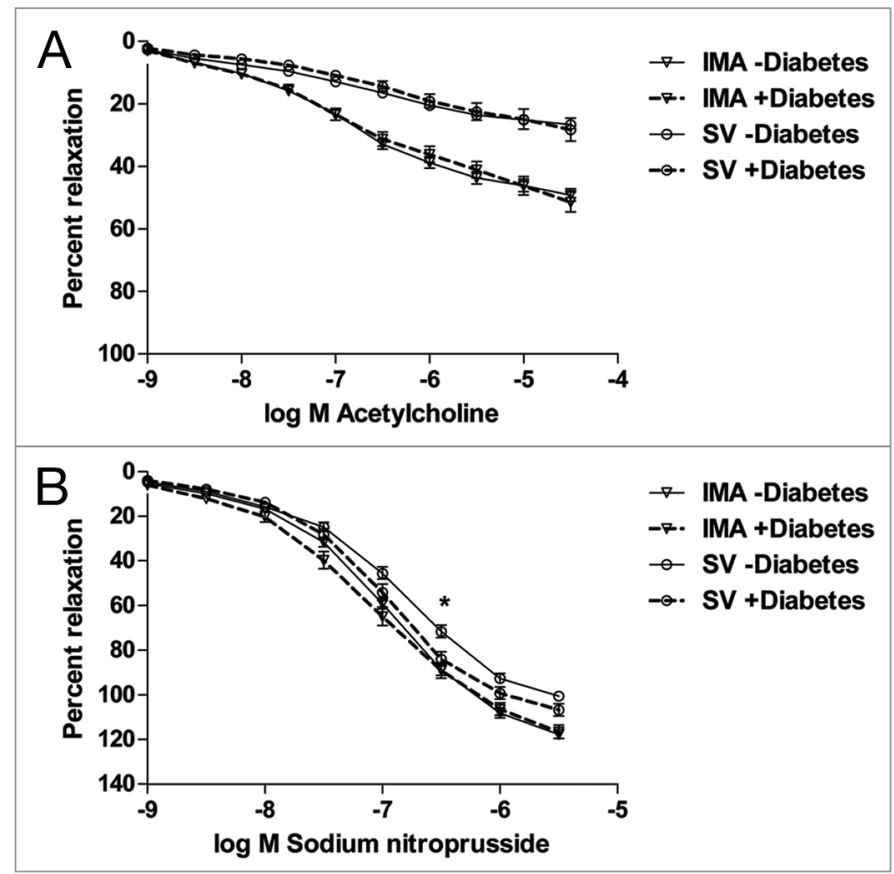

Figure 4. Endothelium-dependent relaxant responses $(A)$ in internal mammary artery (IMA) and saphenous vein (SV) with diabetic $(n=33)$ versus non-diabetic $(n=93)$ patients, and endothelium-independent relaxant responses (B) in IMA and SV with diabetic $(n=20)$ versus nondiabetic $(n=55)$ patients are displayed. Vessel segments are precontracted to a plateau using a sub-maximal dose of phenylephrine, then exposed to increasing concentrations of an endothelium-dependent (acetylcholine) or -independent (sodium nitroprusside) relaxant. Comparisons are made using unpaired repeated measures 2-way ANOVA and individual dose points are compared using Bonferroni posthoc testing, with the indicated doses being significantly different from one another ( $p<0.05$, compared to the other group). The individual data point difference with SV segments is noted above the curve (B). There are no significant differences in endothelium-dependent relaxant responses with either conduit (both $p>0.05, A$ ). Endothelium-independent relaxant responses of SV are significantly better in diabetic versus non-diabetic patients $(p<0.05, B)$ whilst no significant differences are observed with IMA segments. Results are expressed as mean \pm SEM.

are greater than the relaxant responses of SV segments. This is widely described in the literature ${ }^{8,12}$ and merely serves as the startpoint for investigating which particular mechanisms are responsible for this response.

Gender has been shown to be an independent risk factor for long term adverse outcomes following $\mathrm{CABG},{ }^{24}$ with female patients being older and having a greater incidence of risk factors. Women have a lower incidence of coronary artery disease than men of comparable age, with oestrogen seemingly being the protective agent. ${ }^{13,25}$ For a woman to develop coronary disease of adequate severity to require CABG, it is likely that she has to have a greater risk factor burden than a man of comparable age. Enhanced endothelium-dependent relaxant responses in male as compared to female subjects has been previously reported, ${ }^{26,27}$ but is not universal ${ }^{28}$ however, no studies are available comparing endotheliumindependent relaxant responses in male versus female patients. We have demonstrated that both endothelium-dependent and -independent relaxant responses are worse in female patients' SV samples
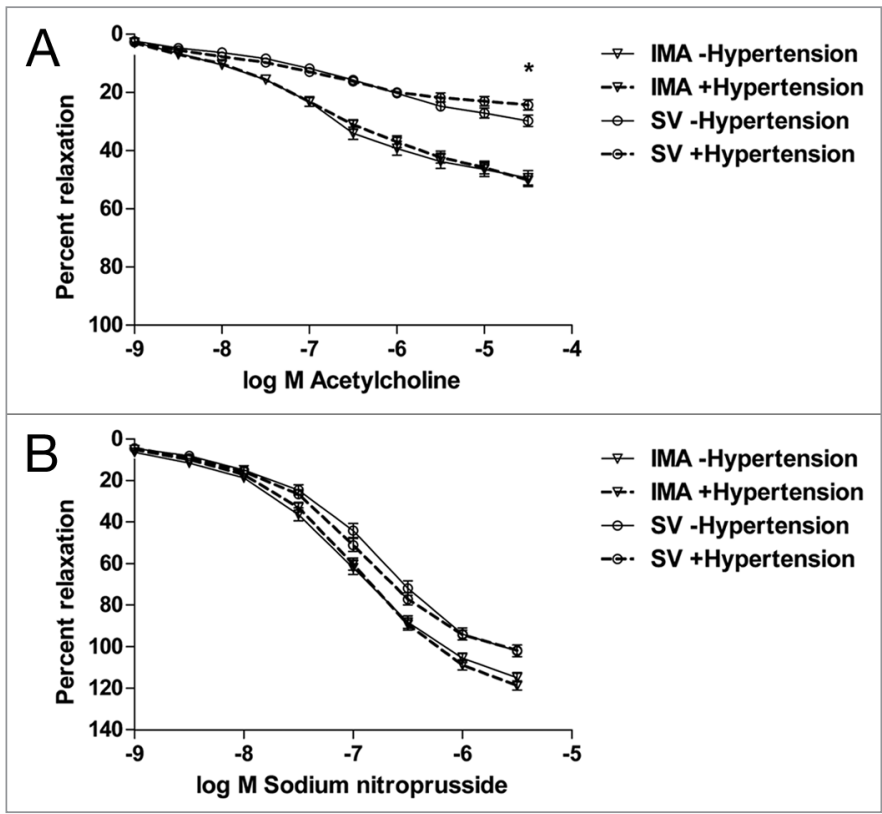

Figure 5. Endothelium-dependent relaxant responses (A) in internal mammary artery (IMA) and saphenous vein (SV) with hypertensive ( $n=67)$ versus non-hypertensive $(n=59)$ patients, and endotheliumindependent relaxant responses (B) in IMA and SV with hypertensive $(n=40)$ versus non-hypertensive $(n=34)$ patients are displayed. Vessel segments are pre-contracted to a plateau using a sub-maximal dose of phenylephrine, then exposed to increasing concentrations of an endothelium-dependent (acetylcholine) or -independent (sodium nitroprusside) relaxant. Comparisons are made using unpaired repeated measures 2-way ANOVA and individual dose points are compared using Bonferroni post-hoc testing, with the indicated doses being significantly different from one another $(p<0.05$, compared to the other group). The individual data point difference with SV segments is noted above the curve (A). Endothelium-dependent relaxant responses of $S V$ are significantly better in non-hypertensive versus hypertensive patients $(p<0.05, A)$ whilst no significant differences are observed with IMA segments. There are no significant differences in endotheliumindependent relaxant responses with either conduit (both $p>0.05, B$ ). Results are expressed as mean \pm SEM.

when compared to their male counterparts. With IMA segments, there was a difference in endothelium-dependent relaxant responses but no difference in endothelium-independent relaxant responses. Together, these data reveal that the gender difference between conduits is due solely to the endothelium with IMA segments, but both endothelium and smooth muscle levels for SV segments. These data uncover a further mechanism that may explain the poorer outcomes of CABG in female patients.

We have demonstrated that hypertension has no effect on endothelium-dependent responses in IMA. This lack of effect in IMA has been demonstrated before, ${ }^{29}$ however other authors have noted decreased endothelial responses in the presence of hypertension. ${ }^{30}$ There are few available vascular reactivity data to which we can compare our SV results, with many authors ${ }^{31-35}$ concentrating upon particular facets of SV response utilising specific chemicals. Although not looking specifically at hypertension per se, Al-Benna and colleagues demonstrated reduced endothelial responses in SV obtained from coronary artery disease patients compared with 


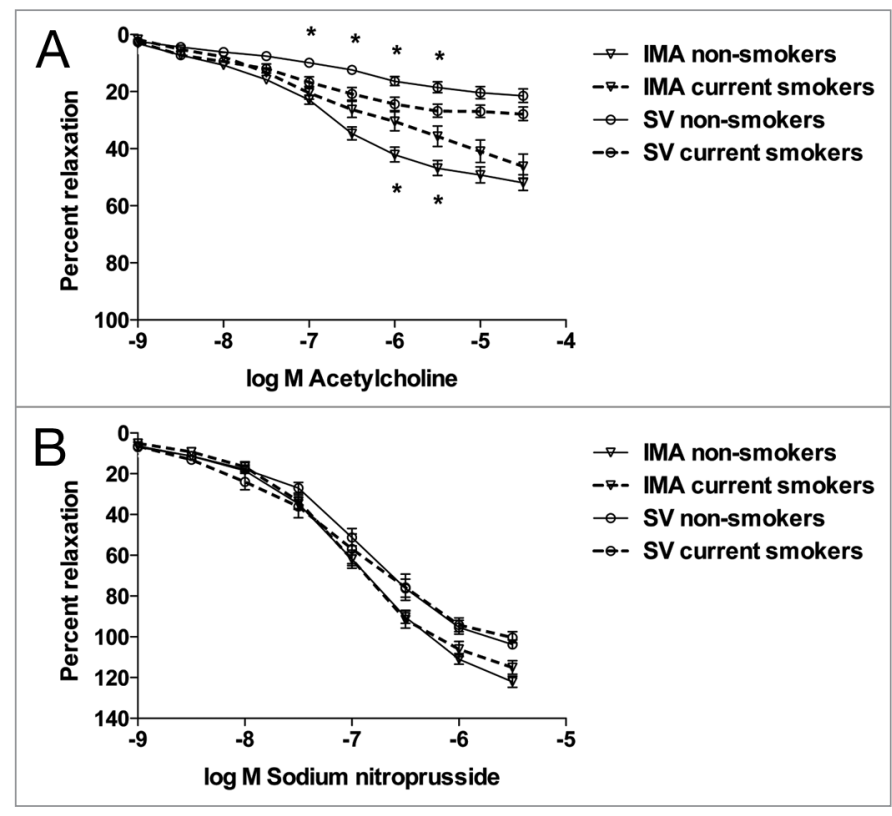

Figure 6. Endothelium-dependent relaxant responses $(A)$ in internal mammary artery (IMA) and saphenous vein (SV) with current $(n=24)$ versus non-smokers $(n=40)$, and endothelium-independent relaxant responses (B) in IMA and SV with current $(n=16)$ versus non-smokers $(n=22)$ are displayed. Vessel segments are pre-contracted to a plateau using a sub-maximal dose of phenylephrine, then exposed to increasing concentrations of an endothelium-dependent (acetylcholine) or -independent (sodium nitroprusside) relaxant. Comparisons are made using unpaired repeated measures 2-way ANOVA and individual dose points are compared using Bonferroni post-hoc testing, with the indicated doses being significantly different from one another $(p<0.05$, compared to the other group). Differences in individual data points with IMA segments are noted below the curves, whilst differences with SV segments are indicated above the curves. The endotheliumdependent relaxant responses in IMA segments of non-smokers are significantly better than those of their smoking counterparts $(p<0.05)$, whilst the responses in SV segments of current smokers are better than those of non-smokers $(p<0.05, A)$. Endothelium-independent relaxant responses of $\mathrm{SV}$ are significantly better in current smokers versus nonsmokers ( $p<0.05$, B) whilst no significant differences are observed with IMA segments. Results are expressed as mean \pm SEM.

control subjects. ${ }^{36}$ The demographic data from their paper shows that the groups were similar except for hypertension and cholesterol level. Therefore, one can conclude that the differences between the control and study patients' SV endothelial responses may be in part due to hypertension and hypercholesterolaemia. Hypertension is associated with increased oxidative stress, caused by either increased activity of oxidant enzymes, and/or dysfunction of anti-oxidant enzymes. ${ }^{37,38}$

There are no differences in endothelium-dependent relaxant responses due to presence of diabetes in either conduit despite the extensive array of potential mechanisms affected, such as a reduction in NO production, overproduction of ROS, reduced levels of antioxidants, increased protein glycosylation and enhanced glucose auto-oxidation. ${ }^{7}$ These data are at odds with some authors, ${ }^{5,39}$ but in agreement with others. ${ }^{14}$ The data pertaining to endothelial (dys)function in diabetic subjects is contradictory, with increased, unchanged and even reduced levels of $\mathrm{NO}$ being reported., ${ }^{70}$
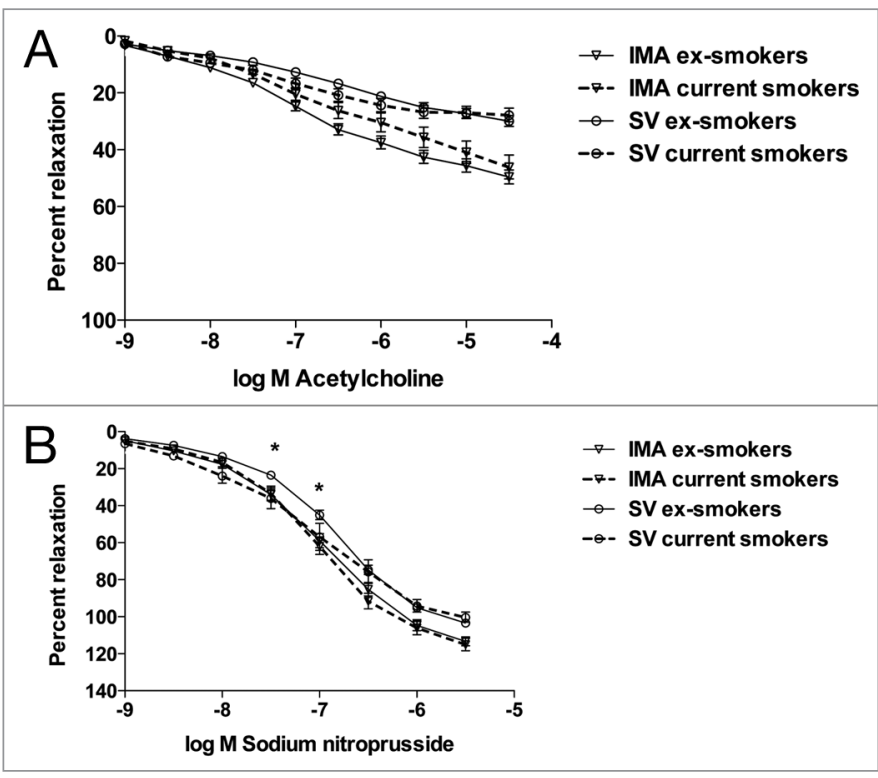

Figure 7. Endothelium-dependent relaxant responses (A) in internal mammary artery (IMA) and saphenous vein (SV) with current $(n=24)$ versus ex-smokers $(n=62)$. Endothelium-independent relaxant responses $(B)$ in IMA and SV with current $(n=16)$ versus ex-smokers $(n=35)$ are displayed. Vessel segments are pre-contracted to a plateau using a submaximal dose of phenylephrine, then exposed to increasing concentrations of an endothelium-dependent (acetylcholine) or -independent (sodium nitroprusside) relaxant. Comparisons are made using unpaired repeated measures 2-way ANOVA, and individual dose points are compared using Bonferroni post-hoc testing, with the indicated doses being significantly different from one another $(p<0.05$, compared to the other group). The individual data point differences with SV segments are noted above the curve (B). The endothelium-dependent relaxant responses in IMA segments of ex-smokers are significantly better than those of their smoking counterparts $(p<0.05, A)$ with no individual dose reaching significance, whilst there are no differences between the responses in SV segments $(p>0.05)$. There are no significant differences in endothelium-independent relaxant responses in IMA segments ( $p$ > 0.05 ), however the endothelium-independent relaxant responses in SV segments of current smokers were better than their ex-smoking counterparts $(p<0.05, B)$. Results are expressed as mean \pm SEM.

There are worsened endothelium-independent responses with nondiabetic as compared to diabetic patients. This effect has not been demonstrated before, the typical data in the literature showing no differences in responses. ${ }^{14}$ We have demonstrated that a given risk factor per se may have a unique effect on vascular relaxation by impairing mechanisms at either endothelial or vascular smooth muscle cell level or a combination of both.

The effect smoking status has on the endothelial responses of the IMA was as expected from the literature, with a reduction in response with increased exposure to inhaled tobacco smoke, and in line with what is seen in the post-operative phase. ${ }^{41}$ The endothelial responses in SV segments were contrary to that expected, and at odds with the behaviour of SV bypass grafts in the post-CABG phase. ${ }^{42,43}$ There are few data available concerning endotheliumindependent conduit responses to smoking, and that data which does exist is contradictory. ${ }^{44,45}$ Clearly there is a more complex relationship between smoking status and vascular function than simple direct injury. A possible explanation is that there is upregulation 
of anti-oxidant capacity in the SV exposed to the various toxins ${ }^{15}$ in tobacco smoke, which, in the controlled environment of the organ bath, without the usual chronic stimuli, may result in superior responses. Cigarette smoke has been shown to promote endothelial regeneration in a rat aortic model ${ }^{46}$ and this accelerated endothelial repair may account for the responses in SV segments. This is at odds with other groups who have shown decreased migration of cultured human umbilical vein endothelial cells with exposure to cigarette smoke..$^{47,48}$

The contractile function of IMA conduits is greater than that of SV conduits when indexed to the conduit size. This is as anticipated, as the IMA is an elastic artery in its proximal course, but more distally where the samples are harvested from, its composition changes to be a muscular artery, termed a 'transition artery', 49 whilst there is only a modest smooth muscle layer present in the SV wall. With a greater proportion of muscle fibres per unit length of conduit, greater forces can be exerted. This ability to contract more strongly does not affect the relaxant responses of IMA conduits, indicating that the important determinant in conduit function is the endothelium, rather than the magnitude of smooth muscle.

Our current data reveal that vascular responses are affected by risk factor status, and this occurs at both the endothelial and smooth muscle levels. These patients were also involved in a range of investigations utilising a number of enzyme inhibitors, ROS-scavengers and second-messenger pathway inhibitors. ${ }^{50}$ Collectively, these data indicate that a number of ROS (particularly $\mathrm{O}_{2}^{--}$) and the interaction between endothelium and smooth muscle is important in the regulation of overall vascular tone, with certain effects being seen at the endothelial level, and others at the vascular smooth muscle level.

Limitations of the study. This investigation has looked at the functional responses of vascular conduits, but no investigation of protein levels, enzyme activity or mRNA expression of the appropriate oxidant and anti-oxidant enzymes has been undertaken. In situations where an unexpected reactivity response has been found, there may well be a simple explanation were these data available.

This investigation focuses solely on two bypass conduits, and does not include the responses in radial arteries. This was due to inadequate numbers of available patient samples.

\section{Materials and Methods}

Patients. Overall, 126 patients undergoing non-emergency coronary artery bypass grafting were recruited for this study. This study had the approval of the local Research Ethics Committee (Queen's University of Belfast) and all patients gave their written informed consent. Vascular samples were harvested from the operating theatres prior to pressure testing of each vessel, thereby avoiding distension injury, and all experiments were commenced within 1 hour of conduit harvest.

Risk factors. Patients were grouped according to their risk factor status concentrating on 4 particular areas: a documented history of hypertension, defined as greater than 140/90 $\mathrm{mmHg}$; the presence or absence of diabetes mellitus, defined as a fasting plasma glucose level greater than $7 \mathrm{mmol} / \mathrm{l}$ or 11.1 $\mathrm{mmol} / \mathrm{l}$ following a glucose load (tolerance test); smoking history with current smoking being defined as having consumed inhaled tobacco smoke within 3 months of operation; and hypercholesterolaemia, with the cut-off point being defined as a total cholesterol $\geq 5.2 \mathrm{mmol} / \mathrm{l}$.

Vascular reactivity. Vascular samples were dissected free of their surrounding tissues in an atraumatic fashion and sharply divided into $2-3 \mathrm{~mm}$ rings. Following calibration of the data acquisition system, these rings were individually mounted between triangular stirrups from isometric force transducers in an 8-bath organ chamber system under physiological conditions in Krebs buffer solution containing (all in mmol/l): $\mathrm{NaCl}$ 118.3, $\mathrm{KCl} 4.7, \mathrm{MgSO}_{4} 1.2, \mathrm{KH}_{2} \mathrm{PO}_{4} 1.2, \mathrm{CaCl} 2.5, \mathrm{NaHCO}_{3}$ 25 , Glucose $11.1, \mathrm{pH} 7.4$, at $37^{\circ} \mathrm{C}$. The solution was gassed with a $95 \% \mathrm{O}_{2}, 5 \% \mathrm{CO}_{2}$ mix. Data were captured from these transducers via an 8-channel data acquisition system (ML780), and recorded in Chart v4 (ADinstruments Ltd., UK). After mounting, the vascular rings were allowed to equilibrate under tension for 90 minutes, with IMA segments being placed under $2.5 \mathrm{~g}$ of tension and SV segments under $1.5 \mathrm{~g}$ of tension.

The first process was to produce a contraction-concentration curve. The vessels were contracted with phenylephrine $(0.001$ to $30 \mu \mathrm{mol} / \mathrm{l})$. Following a washout period, where the vessels returned to baseline tension, a sub-maximal dose was administered, to produce a plateau of contraction. From this plateau of contraction, ten acetylcholine doses (0.001 to 30 $\mu \mathrm{mol} / \mathrm{l})$ were added in a stepwise fashion, eliciting endothelium-dependent relaxant responses. This reagent was used to interrogate risk-factor influence in line with its wide utilisation within the literature. A second washout period then followed. Next, the process was repeated with sodium nitroprusside to demonstrate the contribution direct stimulation of the vascular smooth muscle cells has in these different conduits, with potentially different populations of smooth muscle cells. Eight stepwise doses $(0.001$ to $3 \mu \mathrm{mol} / \mathrm{l})$ of this commonly used reagent within the vascular reactivity field assessed endothelium-independent relaxant responses. Following a final washout period, the vascular rings were subjected to a high potassium concentration $(120 \mathrm{mmol} / \mathrm{l})$ to directly stimulate the smooth muscle, bypassing all pathways, and confirming viability of the sample. The rings were air-dried overnight, and then weighed to index their contractions.

Statistical analysis. Analysis of relaxant responses was undertaken using repeated measures two-way ANOVA in all cases, with risk factor comparisons being unpaired. The relaxant responses analyses were performed using Prism v4 for Windows (GraphPad Software, San Diego, CA).

\section{Acknowledgements}

This investigation was supported by a HPSS training Fellowship (A.D.M.) provided by the Research and Development Office, Northern Ireland, reference EAT/2204/02. We are very grateful to the cardiac surgical teams, Royal Victoria Hospital, Belfast for their assistance with the provision of tissue samples.

References 
1. Taggart DP. Surgery is the best intervention for severe coronary disease. Br Med J 2005; 330:785-6.

2. Loop FD, Lytle BW, Cosgrove DM, Stewart RW, Goormastic M, Williams GW, et al. Influence of the internal-mammary-artery graft on 10-year survival and other cardiac events. N Engl J Med 1986; 314:1-6.

3. Endo M, Tomizawa Y, Nishida H. Bilateral versus unilateral internal mammary revascularisation in patients with diabetes. Circulation 2002; 108:1343-9.

4. Lytle BW, Blackstone EH, Sabik JF, Houghtaling P, Loop $\mathrm{FD}$, Cosgrove DM. The effect of bilateral internal thoracic artery grafting on survival during 20 postoperative years. Ann Thorac Surg 2004; 78:2005-14.

5. Pompilio G, Rossoni G, Alamanni F, Tartara P, Barajon I, Rumio C, et al. Comparison of endotheliumdependent vasoactivity of internal mammary arteries from hypertensive, hypercholesterolaemic and diabetic patients. Ann Thorac Surg 2001; 72:1290-7.

6. Furumoto T, Saito N, Dong J, Mikami T, Fujii S, Kitabatake A. Association of cardiovascular risk factors and endothelial dysfunction in Japanese hypertensive patients: implications for early atherosclerosis. Hypertens Res 2002; 25:475-80.

7. Bayraktutan U. Free radicals, diabetes and endothelial dysfunction. Diabet Obes Metabol 2002; 4:224-38.

8. Hamilton CA, Berg G, McIntyre M, McPhaden AR, Reid JL, Dominiczak AF. Effects of nitric oxide and superoxide on relaxation in human artery and vein. Atherosclerosis 1997; 133:77-86.

9. Cable DG, Caccitolo JA, Pfeifer EA, Daly RC, Dearan JA, Mullany CJ, et al. Endothelial regulation of vascular contraction in radial and internal mammary arteries. Ann Thorac Surg 1999; 67:1083-90.

10. Berry B, Hamilton CA, Brosnan J, Magill FG, Berg GA, McMurray JJV, et al. Investigation into the sources of superoxide in human blood vessels. Angiotensin II increases superoxide production in human internal mammary arteries. Circulation 2000; 101:2206-12.

11. Hamilton CA, Brosnan MJ, Al-Benna S, Berg G, Dominiczak AF. NAD (P)H oxidase inhibition improves endothelial function in rat and human blood vessels. Hypertension 2002; 40:755-62.

12. Guzik TJ, Sadowski J, Kapelak B, Jopek A, Rudzinski P, Pillai R, et al. Systemic regulation of vascular NAD(P) $\mathrm{H}$ oxidase activity and nox isoform expression in human arteries and veins. Arterioscler Thromb Vasc Biol 2004; 24:1614-20.

13. Nechmad A, Merin G, Schwalb H, Shimon DV, Borman JB, Milgalter E, et al. Estrogen induces nitric oxide-mediated vasodilation of human mammary arteries in vitro. Nitric Oxide 1998; 2:460-6.

14. Wendler O, Landwehr P, Bandner-Risch D, Georg T, Schäfers H-J. Vasoreactivity of arterial grafts in the patient with diabetes mellitus: investigations on internal thoracic artery and radial artery conduits. Eur J Cardiothoracic Surg 2001; 20:305-11.

15. Barua RS, Ambrose JA, Eales-Reynolds L, DeVoe MC, Zervas JG, Saha DC. Dysfunctional endothelial nitric oxide biosynthesis in healthy smokers with impaired endothelium-dependent vasodilatation. Circulation 2001; 104:1905-10

16. Yang ZW, Zheng T, Zhang A, Altura BT, Altura BM. Mechanisms of hydrogen peroxide-induced contraction of rat aorta. Eur J Pharmacol 1998; 344:169-81.

17. Yang ZW, Zhang A, Altura BT, Altura BM. Hydrogen peroxide-induced endothelium-dependent relaxation of rat aorta. Involvement of $\mathrm{Ca}^{2+}$ and other cellular metabolites. Gen Pharmacol 1999; 33:325-36.

18. Furchgott RF, Zawadzki JV. The obligatory role of endothelial cells in the relaxation of arterial smooth muscle by acetylcholine. Nature 1980; 288:373-6.

19. Ignarro LJ, Buga GM, Wood KS, Byrns RE. Endothelium-derived relaxing factor produced and released from artery and vein is nitric oxide. Proc Nat Acad Sci USA 1987; 84:9265-9.

20. Landmesser U, Hornig B, Drexler H. Endothelial function. A critical determinant in atherosclerosis? Circulation 2004; 109:27-33.
21. Luscher TF, Diederich D, Siebenman R, Lehmann K, Stulz P, von Segesser L, et al. Difference between endothelium-dependent relaxation in arterial and in venous coronary bypass grafts. N Eng J Med 1988; 319:462-7.

22. Schächinger V, Britten MB, Zeiher AM. Prognostic impact of coronary vasodilator dysfunction on adverse long-term outcome of coronary heart disease. Circulation 2000; 101:1899-906.

23. Demirci B, McKeown PP, Bayraktutan U. The bimodal regulation of vascular function by superoxide anion: role of endothelium. BMB reports 2008; 41:223-9.

24. Hassan A, Chiasson M, Buth K, Hirsch G. Women have worse long-term outcomes after coronary artery bypass grafting than men. Can J Cardiol 2005; 21:757-62.

25. Stefano GB, Prevot V, Beauvilain J-C, Cadet P, Fimiani $\mathrm{C}$, Welters I, et al. Cell-surface estrogen receptors mediate calcium-dependent nitric oxide release in human endothelia. Circulation 2000; 101:1594-7.

26. Huraux C, Makita T, Kurz S, Yamaguchi K, Szlam F, Tarpey MM, et al. Superoxide production, risk factors and endothelium-dependent relaxations in human internal mammary arteries. Circulation 1999; 99:53-9.

27. Akar F, Manavbasi Y, Parlar AI, Ulus AT, Katircioglu SF. The gender differences in the relaxation to levosimendan of human internal mammary artery. Cardiovasc Drugs Ther 2007; 31:331-8.

28. Figtree GA, Guzik T, Robinson BG, Channon KM, Watkins H. Functional estrogen receptor alpha promoter polymorphism is associated with improved endothelial-dependent vasodilation. Int J Cardiol 2009; In press.

29. Deja MA, Golbs KS, Wos S, Mrozek R, Bachowski $\mathrm{R}$, Biernat J. Internal mammary artery graft function is not affected in hypertensive patients on therapy. Cardiovasc Surg 1997; 5:367-75.

30. Turoni CM, de Bruno MP, Coviello A, Marañón RO, Herrera RN, Muntaner J, et al. Internal mammary artery grafts reactivity in hypertensive patients: role of stretching in extraendothelial nitric oxide. Clin Exp Hypertens 2007; 29:327-44.

31. Yang Z, von Segesser L, Bauer E, Stulz P, Turina M, Lüscher TF. Different activation of the endothelia L-arginine and cyclooxygenase pathway in the human internal mammary artery and saphenous vein. Circ Res 1991; 68:52-60.

32. Cracowski J-L, Stanke-Labesque F, Sessa C, Hunt M, Chavanon O, Devillier P, et al. Functional comparison of the human isolated femoral artery, mammary artery, gastroepiploic artery and saphenous vein. Can J Physio Pharmacol 1999; 77:770-6.

33. Shapira OM, Xu A, Aldea GS, Vita JA, Shemin RJ, Keaney JF. Enhanced nitric oxide-mediated vascula relaxation in radial artery compared with internal mammary artery or saphenous vein. Circulation 1999; 100:322-7.

34. Sogo N, Campanella C, Webb DJ, Megson IL. $\mathrm{S}$-nitrosothiols cause prolonged, nitric oxide-mediated relaxation in human saphenous vein and internal mammary artery; therapeutic potential in bypass surgery. $\mathrm{Br}$ J Pharmacol 2000; 131:1236-44.

35. Gruhn N, Boesgaard S, Eiberg J, Bang L, Thiis J, Schroeder TV, et al. Effects of large $\mathrm{Ca}^{2+}$-activated $\mathrm{K}^{+}$ channels on nitroglycerin-mediated vasorelaxation in humans. Eur J Pharmacol 2002; 446:145-50.

36. Al-Benna S, Hamilton CA, McClure JD, Rogers PN, Berg GA, Ford I, et al. Low-density lipoprotein cholesterol determines oxidative stress and endothelial dysfunction in saphenous veins from patients with coronary artery disease. Arterioscler Thromb Vasc Biol 2006; 26:218-23.

37. Ghosh M, Wang HD, McNeill JR. Role of oxidative stress and nitric oxide in regulation of spontaneous tone in aorta of DOCA-salt hypertensive rats. $\mathrm{Br} J$ Pharmacol 2004; 141:562-73.
38. Kerr S, Brosnan MJ, McIntyre M, Reid JL, Dominiczak AF, Hamilton CA. Superoxide anion production is increased in a model of genetic hypertension. Role of the endothelium. Hypertension 1999; 33:1353-8.

39. Chello M, Spadaccio C, Lusini M, Covino E, Blarzino C, De Marco F, et al. Advanced glycation end products in diabetic patients with optimized glycaemic control and their effects on endothelial reactivity: possible implications in venous graft failure. Diabetes Metab Res Rev 2009; 25:420-6.

40. Chatterjee A, Catravas JD. Endothelial nitric oxide (NO) and its pathophysiologic regulation. Vasc Pharmacol 2008; 49:134-40.

41. Kunadian B, Dunning J, Millner RWJ. Modifiable risk factors remain significant causes of medium term mortality after first time coronary artery bypass grafting. J Cardiothorac Surg 2007; 2:51.

42. Domanski MJ, Borkowf CB, Campeau L, Knatterud GL, White C, Hoogwerf B, et al. and the Post-CABG Trial Investigators. Prognostic factors for atherosclerosis progression in saphenous vein grafts. The postcoronary artery bypass graft (Post-CABG) Trial. J Am Coll Cardiol 2000; 36:1877-83.

43. Lindsay GM, Tolmie EP, Martin WM, Hutton IM, Belcher PR. Smoking after coronary artery bypass: high three-year mortality. Thorac Cardiovasc Surg 2009; 57:135-40.

44. Guthikonda S, Sinkey CA, Haynes WG. What is the most appropriate methodology for detection of conduit artery endothelial dysfunction? Arterioscler Thromb Vasc Biol 2007; 27:1172-6.

45. Edvinsson ML, Anderson SE, Xu CB, Edvinsson L. Cigarette smoking leads to reduced relaxant responses of the cutaneous microcirculation. Vasc Health Risk Manag 2008; 4:699-704.

46. Sarkar R, Gelabert HA, Mohiuddin KR, Thakor DK, Santibanez-Gallerani AS. Effect of cigarette smoke on endothelial regeneration in vivo and nitric oxide levels. J Surg Res 1999; 82:43-7.

47. Sbajdar RM, Busuttil SJ, Averbook A, Graham DJ. Inhibition of endothelial cell migration by cigarette smoke condensate. J Surg Res 2001; 96:10-6.

48. Michaud SE, Dussault S, Groleau J, Haddad P, Rivard A. Cigarette smoke exposure impairs VEGF-induced endothelial cell migration: role of $\mathrm{NO}$ and reactive oxygen species. J Mol Cell Cardiol 2006; 41:275-84.

49. Canham PB, Finlay HM, Boughner DR. Contrasting structure of the saphenous vein and internal mammary artery used as coronary bypass vessels. Cardiovasc Res 1997; 34:557-67.

50. Muir AD, McKeown PP, Bayraktutan U. The role of oxidative stress in modulation of the relaxant response of saphenous vein and internal mammary artery. Open Circ Vascu J 2010; In press. 


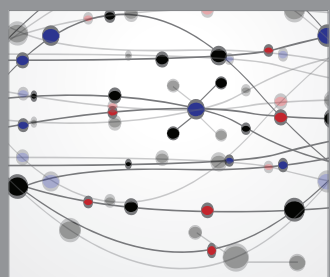

The Scientific World Journal
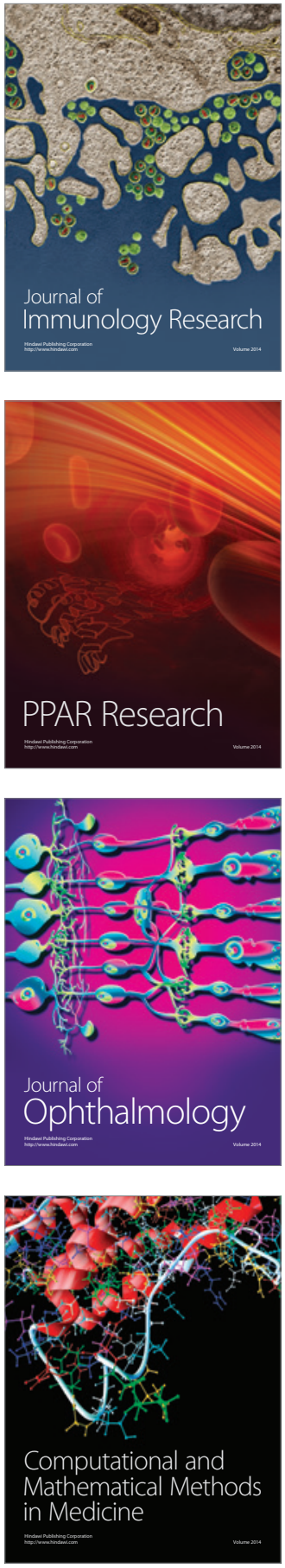

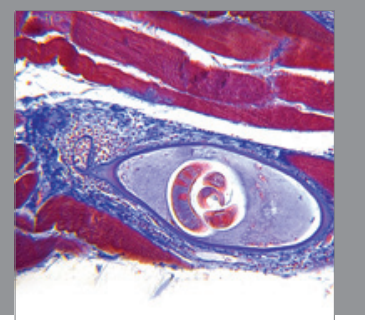

Gastroenterology

Research and Practice
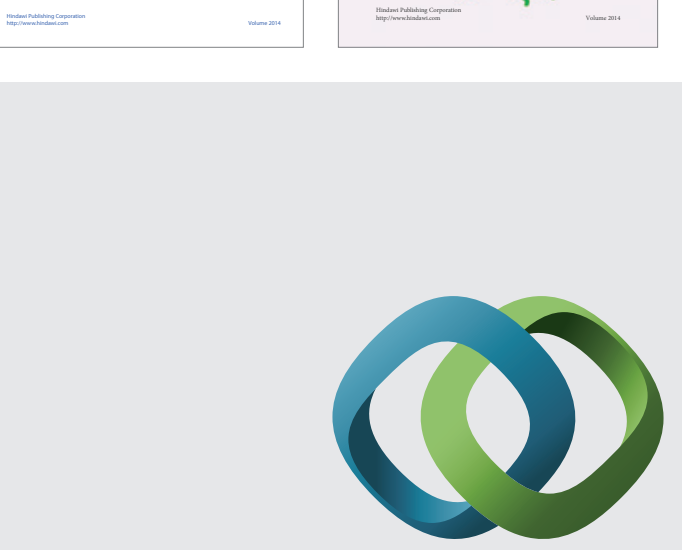

\section{Hindawi}

Submit your manuscripts at

http://www.hindawi.com
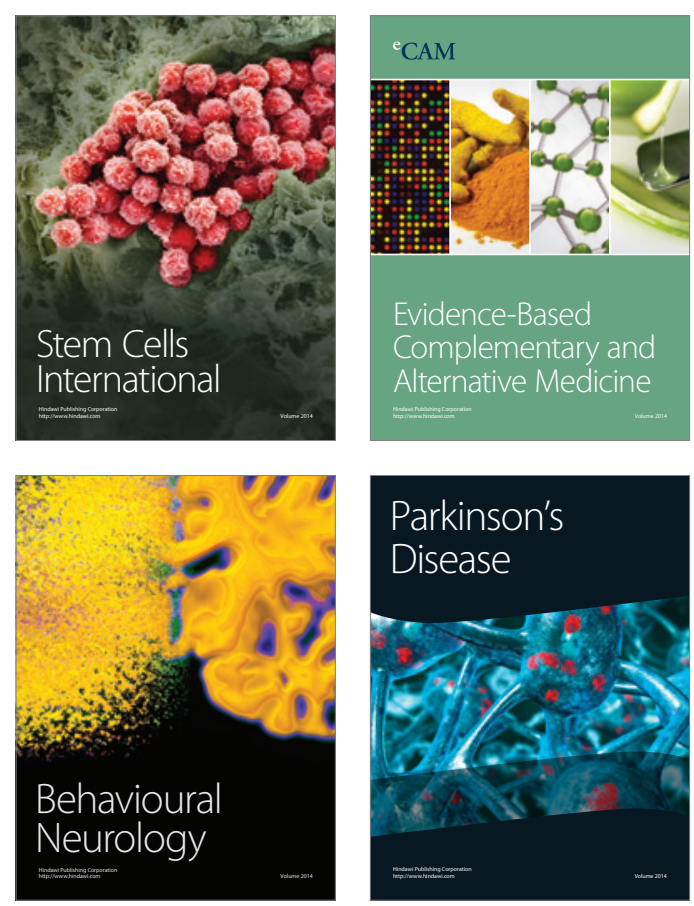

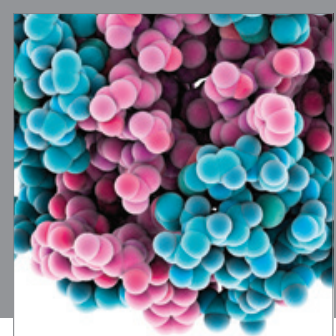

Journal of
Diabetes Research

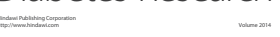

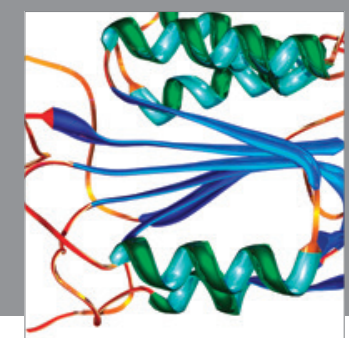

Disease Markers
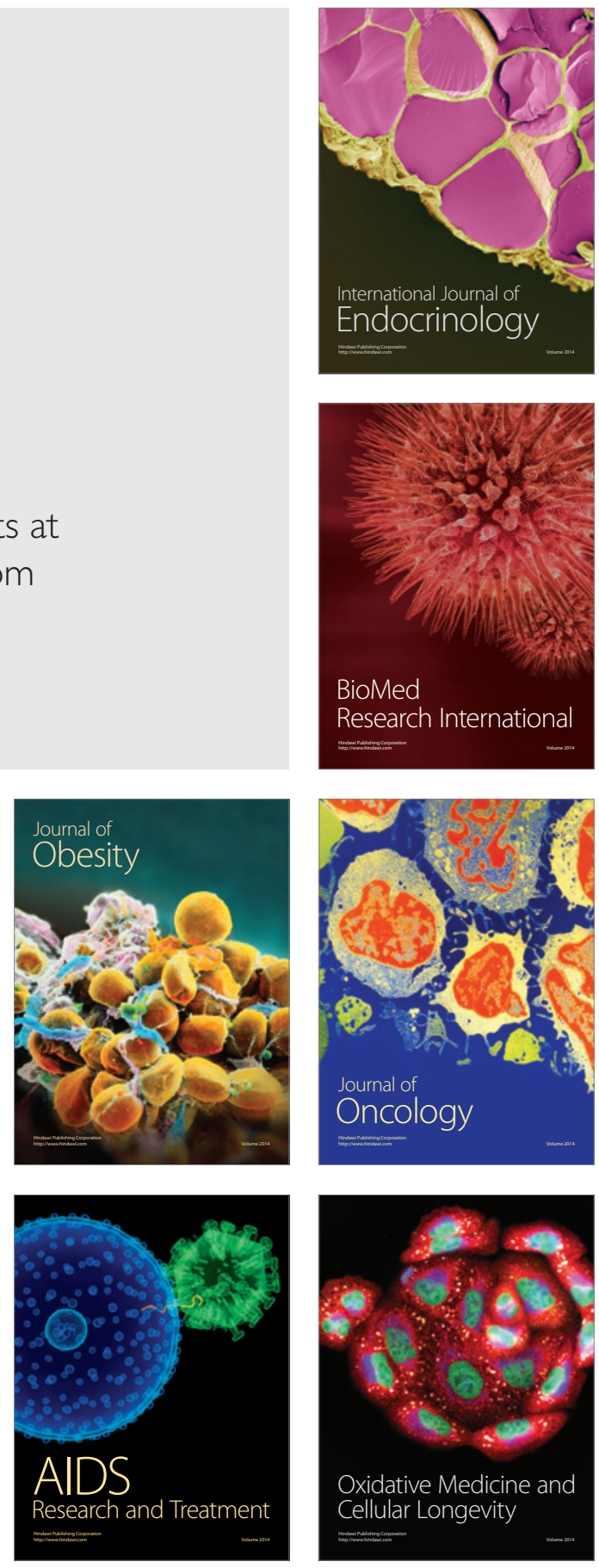